\title{
A hipótese dos territórios qualificantes no trabalho com informação
}

\author{
The qualifying territories hypotheses in the work with information
}

Leonora Corsini

Doutora em Serviço Social pela Universidade Federal do Rio de Janeiro - UFRJ

Pesquisadora associada do Laboratório Território e Comunicação da UFRJ

E-mail: corsinileonora@gmail.com

\begin{abstract}
Resumo
O artigo trata das novas dinâmicas produtivas e configurações do trabalho que caracterizam o que vem sendo designado como trabalho cognitivo, um tipo de trabalho que tem como principal suporte as redes e relações tecidas no território metropolitano. Examinamos essas novas configurações em articulação com a hipótese dos "territórios qualificantes", lugar onde novas competências são modeladas a partir das ações e das experiências do trabalho cognitivo em rede, competências estas que retornam para o território na forma de serviços que têm como elementos centrais a inteligência colaborativa, a criatividade e a inovação. Com base nessas premissas, iniciamos um estudo de caso que teve como objeto o trabalho dos técnicos prestadores de serviço em informática, os quais, com seus diferentes níveis de formação e especialização, são fundamentais para o desenvolvimento do trabalho cognitivo no âmbito das metrópoles. Os resultados preliminares indicaram que entre os técnicos de informática predomina a combinação de dois modelos de trabalho: autônomo e assalariado, modelos que se alimentam reciprocamente e estabelecem uma relação de mão dupla. Pudemos igualmente confirmar a conexão entre as novas tecnologias e linguagens, o trabalho em rede, as novas dinâmicas produtivas, e a possibilidade de aprender a partir da instabilidade e das constantes mutações que caracterizam o meio informático, podendo fazer isto coletivamente, nos marcos da cooperação e da comunicação.
\end{abstract}

Palavras chave: Trabalho cognitivo; Metrópole; Territórios qualificantes; Cooperação e criação

\begin{abstract}
The paper addresses the new productive dynamics and labor configurations characteristic of the so called cognitive labor, which has the networks and relations built in the metropolitan territory among its main support. We examined these new configurations in articulation with the thesis of the "qualifying territories", the place where new competences are modeled and return to the territory in the form of services that hold among their central elements the collaborative intelligence, creativity and innovation. Departing from these assumptions, we initiated a case study focusing the self employed digital workers who bear varied levels of education and specialization, regarded as fundamental agents for the development of the cognitive labor in contemporary metropolises. Preliminary results indicate predominance among these workers of a mix of two regimes of labor: autonomous and salaried, coextensively establishing a bilateral relationship. We could equally confirm the connection between new technologies and languages, collaborative networks, new productive dynamics and the possibility of learning from instability and constant mutations that characterize the informatics environment, rendered possible through the collective action, in the marks of cooperation and communication.
\end{abstract}

Keywords: Cognitive labor; Metropolis; Qualifying territories; Cooperation and creation 


\section{Introdução}

As transformações do trabalho e seus efeitos na organização e nas dinâmicas produtivas do mundo contemporâneo vêm colocando em foco os trabalhadores autônomos e os trabalhadores que estão inseridos em um regime de acumulação característico de um novo momento do capitalismo, aquilo que atualmente vem sendo designado como Capitalismo Cognitivo.

Essas transformações têm a ver com a passagem a um novo regime de acumulação e criação de valor que, por sua vez, remete à passagem do modelo fabril - o fordismo - para o modelo pós-industrial - ou pós-fordismo. Este deslocamento de um modelo fordista (baseado no paradigma da grande indústria) ao modelo pós-fordista (baseado no conhecimento), implica também uma profunda transformação do trabalho. Com efeito, podemos definir essa transformação como o deslocamento da centralidade do trabalho material para o que o próprio Marx definia como "trabalho imaterial", um regime de acumulação globalizado e organizado em redes integradas de produção e circulação que oferece um caminho consistente diante da multiplicação das análises que apostavam na emergência de um modelo neo-industrial: o toyotismo (PIORE; SABEL, 1984; CORIAT, 1994, entre outros). Hoje em dia ninguém coloca a trajetória japonesa como paradigma do pós-fordismo. Além disto, a abordagem em termos de trabalho imaterial permitiu ir além do impasse determinado pelas teorias do "adeus ao proletariado" (GORZ, 1982), do "fim do trabalho" (RIFKIN, 2004), do "deslocamento do trabalho para o consumo" (CANCLINI, 1995 e, bem antes dele, Albert O. HIRSCHMAN, 1973). Christian Marazzi (2009, p. 26) observa que com o pós-fordismo a comunicação entra na produção, tornando-se fator diretamente produtivo. Neste processo, ganha destaque a linguagem, que se encontra na base do ato de comunicar, reforçando a coincidência entre os atos de produzir e comunicar. A partir daí, abre-se um leque de possibilidades de análise dos nexos entre "o modo de produção por meio da comunicação" e seus possíveis aspectos políticos. Hoje temos produção de conhecimento por meio do conhecimento, produção da vida por meio da vida (MOULIER-BOUTANG, 2007). Ou, nos termos de Franco Berardi (2005), um trabalho que é "trabalho da comunicação, ou comunicação empenhada em trabalhar".

Além disto, no marco do trabalho imaterial, é a força de invenção, muito mais do que a força de trabalho, que se encontra mobilizada, fazendo com que a produção da população ativa resulte na produção de conhecimento e da própria vida, além de bens e serviços. E, na 
medida em que este novo tipo de produção tende a se disseminar como trabalho cognitivo, a cooperação social encontra na rede digital seu âmbito mais apropriado. Na proposição de Berardi (2005), o trabalho cognitivo se expressa como infotrabalho, ou seja, uma infinita recombinação de milhares de informações que circulam num suporte de tipo digital. Segundo este autor, todo infotrabalhador é portador da capacidade de elaboração de um segmento semiótico que deve se encontrar e se integrar com inúmeros outros fragmentos semióticos para compor o quadro de uma combinatória, a "infomercadoria", o "semiocapital". Esse trabalhador move-se continuamente para encontrar sinais, elaborar experiências ou seguir os percursos naturais de sua existência. Em cada momento e lugar ele é alcançável e pode ser chamado de novo a exercer sua função produtiva e se reinserir no ciclo global da infoprodução - através de ferramentas como celular, messenger, orkut, e outros sites e redes sociais. Assim, trabalhar hoje significa "mover-se, deslocar-se, mudar de perspectiva, de relações" [...]. E o trabalho cognitivo é, sobretudo, "trabalho da comunicação, ou comunicação empenhada em trabalhar" (idem).

Desta maneira, dizer que o trabalho hoje se tornou imaterial e cognitivo significa afirmar que, no pós-fordismo, são as dimensões intersubjetivas do trabalho que determinam as dimensões objetivas (aquelas da relação sujeito/objeto) típicas do processo de trabalho industrial. Isso não significa que o trabalho material tenha desaparecido por completo, menos ainda equivale a identificar o trabalho imaterial ou cognitivo com meras funções "intelectuais". Pelo contrário, trata-se de dar conta do fato de que, como o próprio Marx antecipava, "o produto deixa de ser criado pelo trabalhador individual imediato para ser o resultado mais de uma combinação de atividade social que da simples atividade do produtor". A transformação da matéria pelo trabalhador individual (inclusive quando ele continua no chão de fábrica) depende de dinâmicas imateriais, quais sejam: dinâmicas comunicativas, linguísticas, afetivas, em suma, atividades que englobam a mente e a mão de um trabalhador de carne e osso.

O trabalho passa a ser, como diz Maurizio Lazzarato (2006), um modo de captura da cooperação entre cérebros que resulta na produção ou "efetuação de mundos". Invertendo a definição de Marx, Lazzarato afirma que o capitalismo não diz apenas respeito aos modos de produção (modes de production), mas é, sobretudo, produção de mundos (production de mondes). O capitalismo é uma efetuação dos mundos e das subjetividades nele inseridas, bem como criação e realização de desejos, crenças e inteligências que antecedem, que são primeiras em relação à produção econômica. 
Do ponto de vista da qualificação para o trabalho, verificamos igualmente um deslocamento bastante visível: se antes as empresas dependiam da qualidade da mão-de-obra disponível e tinham que se adaptar a ela, agora o sistema produtivo procura pautar seu mercado de trabalho ideal, mobilizando e modulando competências que, uma vez ativadas, dão forma e "renormatizam" as organizações e agentes que compõem esse mercado. Ou seja, verifica-se um deslocamento da perspectiva da qualificação para o trabalho (ou emprego) para a perspectiva de um trabalho que qualifica, um trabalho "qualificante". E esta nova característica do trabalho contemporâneo, na visão de analistas como Philippe Zarifian (2003; 1995), por exemplo, faz com que hoje as organizações e empresas se também constituam em lugares de construção de conhecimento e de aquisição de competências. Daí Zarifian denominá-las "organizações qualificantes".

\section{O trabalho como acontecimento e invenção}

Em À quoi sert le travail? (2003) Philippe Zarifian redireciona o foco sobre a questão do trabalho que, segundo ele, teria ficado ofuscada pela problemática do emprego, fazendo com que todos se esquecessem que o problema do emprego ou mesmo do desemprego é, antes de tudo, uma questão do trabalho. Sua proposta é pensar o trabalho como atividade, como ação, como devir e como acontecimento.

Duas possíveis linhas de análise poderiam, de acordo com Zarifian, dar uma resposta à questão que ele levanta, "para quê serve o trabalho?": uma visão estrutural, ou puramente funcional - trabalhar é ocupar uma função - cuja lógica é norteada pela divisão do trabalho, da coordenação das diferentes tarefas, do controle da execução, sob a marca da prescrição, da reprodução e do desempenho; e uma visão estratégica, que analisa o trabalho como pura relação de forças - trabalhar é resistir a um poder hierárquico. Nesta perspectiva, raciocina-se em termos de dominação, exploração, submissão; aos trabalhadores assalariados não resta

\footnotetext{
${ }^{1}$ Organização qualificante é o nome dado na França à "organização aprendente" ou "learning organization", lugar de aprendizado de competências mais adequadas à complexidade do mercado de trabalho. Trata-se de um aprendizado sempre atrelado à experiência e ao acontecimento (seja ele provocado ou aleatório), convergindo assim para a definição de André Gorz (2005) dos saberes vivos. A resposta do trabalhador ao surgimento do imprevisível, do incerto, dos acontecimentos, é dada pela mobilização da atenção individual e coletiva ao que está se passando, ao que já passou e ao que vai passar. Isto significa invenção, capacidade de agenciamento, de combinações, de fazer acontecer. "A organização qualificante, na medida em que favorece, simultaneamente, a aquisição de competências no seio da organização e sobre a organização situa-se numa dialética verdadeiramente singular e, neste caso, inédita. A organização deve permitir, no seu seio, as aprendizagens a ela relativas!" (ZARIFIAN, 1995).
}

InCID: R. Ci. Inf. e Doc., Ribeirão Preto, v. 1, n. 2, p. 89-102, jul./dez. 2010. 
outra saída senão resistir, ou utilizar as margens e as brechas que o poder patronal deixa abertas.

Zarifian também opta por uma perspectiva de análise que ressalta o poder da ação, mas aqui buscando resgatar a potência das individualidades que trabalham, numa leitura que atualiza o conceito de mônadas de Leibniz, via Gabriel Tarde, para pensar de maneira bastante inovadora a subjetividade dos trabalhadores ${ }^{2}$. As individualidades que trabalham, ou singularidades em ação, exercitam e materializam, através do trabalho, a potência do pensamento e a capacidade de dar sentido e engendrar subjetividades, uma ação que se efetua através da interdependência e da cooperação das subjetividades, passando da operação à ação, e do trabalho em equipe à atividade em rede. E o exercício desta potência é primeiro e irremediável, mesmo no caso dos trabalhos mais, digamos, "taylorizados". O trabalho passa a ser muito mais invenção do que imitação e reprodução; trata-se de uma multidão de invenções e sua constante difusão e entrecruzamentos na base e na origem de tudo o que os indivíduos produzem, no cotidiano de sua atividade laboral.

Contudo, a importância da invenção não pode ser plenamente compreendida se não se lança mão do conceito de acontecimento - central na proposição de Zarifian e também na de Maurizio Lazzarato: trabalhar é se confrontar permanentemente com situações imprevistas, interditas, imprevisíveis, e contra-efetuar essas situações e acontecimentos conferindo a eles um sentido humano, e agir em resposta a eles. O trabalho é atravessado por acontecimentos singulares, que obrigam a inventar, a inventar um pensamento, uma linha de ação, a despeito e na contramão de todas as tentativas de racionalização e padronização. Ou seja, o trabalho é visto como produção de possíveis, em que o possível (um produto, um serviço) expressa um mundo que precisa o tempo todo ser criado, um mundo que não é dado a priori. "O mundo, os trabalhadores, os consumidores, não preexistem aos acontecimentos. São, ao contrário, engendrados pelo acontecimento" (LAZZARATO, 2006, p. 108). Seguindo esta nova perspectiva do trabalho, a invenção e a efetuação dos possíveis é a verdadeira produção, e esta atividade de criação e produção de mundos e subjetividades é apropriada também pela empresa contemporânea. E capturar a criação, conclui Lazzarato, é capturar o próprio acontecimento:

Mesmo nas fábricas, um dos berços das técnicas disciplinares, a organização do trabalho passa a ser investida da lógica do acontecimento, pelo agenciamento da diferença e repetição" (idem). O trabalho torna-se assim um conjunto de acontecimentos, "de coisas que chegam de maneira não previsível, constituindo

\footnotetext{
${ }^{2}$ Ver também, a este respeito, As revoluções do capitalismo de Maurizio Lazzarato (2006, p. 111).
}

InCID: R. Ci. Inf. e Doc., Ribeirão Preto, v. 1, n. 2, p. 89-102, jul./dez. 2010. 
exceções com relação à situação considerada normal (ZARIFIAN, 2003, p. $95^{3}$ apud LAZZARATO, 2006, p. 108-109).

Prosseguindo com a proposição de trabalho como acontecimento, Zarifian diz que a resposta (do trabalhador) ao surgimento do imprevisível, do incerto, dos acontecimentos, é dada pela mobilização da atenção individual e coletiva ao que está se passando, ao que já passou e ao que vai passar, e isso significa invenção, capacidade de agenciamento, de combinações, de fazer acontecer. Acontecimentos e invenções se distribuem ao longo do ciclo de produção e se articulam às rotinas, aos hábitos e às operações codificadas. Marx já havia dito que o trabalho passaria a ser uma atividade de controle da produção, ao invés de uma atividade direta de transformação da matéria e é exatamente isto que estamos vendo acontecer no capitalismo contemporâneo: controlar significa prestar atenção aos acontecimentos, e trabalhar é estar atento aos acontecimentos, quer se produzam no mercado, quer sejam produzidos pela clientela ou no escritório: é colocar em marcha uma capacidade de agir, de antecipar, de estar à altura dos acontecimentos, o que implica poder aprender não só com a experiência, mas com a incerteza e as mudanças, poder tornar-se ativo diante das instabilidades e produzir em conjunto, a partir dos "marcos comunicacionais" e, poderíamos acrescentar, "marcos linguísticos e informacionais".

Franco Berardi, (2005) refaz a indagação de Zarifian lançando a pergunta: "O que significa trabalhar hoje? De acordo com Berardi, o trabalho se tornou, por um lado, muito mais uniforme, do ponto de vista físico, ergonômico; e, por outro lado, o trabalho é hoje muito mais diferenciado no que se refere aos conteúdos que elabora (BERARDI, 2005, p. 38).

\footnotetext{
O trabalho se tornou parte de um processo mental, elaboração de sinais densos de saber. Tornou-se muito mais específico, muito mais especializado: o advogado, o arquiteto, o técnico de informática e o caixa do supermercado estão diante da tela do mesmo monitor e batem nas mesmas teclas, mas um não poderia nunca assumir o posto do outro, porque o conteúdo de sua atividade de elaboração é irredutivelmente diverso e intransferível (ibidem, p. 39).
}

Consequentemente, os trabalhadores contemporâneos tendem a considerar o trabalho a parte mais essencial de sua vida, a parte mais singular e mais personalizada. Exatamente o contrário do que acontecia com o operário industrial, para o qual a jornada de oito horas de trabalho era uma espécie de morte temporária da qual as pessoas se livravam quando soava a sirene de fim de horário.

Assim, o novo trabalhador, o infotrabalhador ou trabalhador high-tech, nas definições

\footnotetext{
${ }^{3}$ ZARIFIAN, P. À quoi sert le travail? Paris: La Dispute, 2003
}

InCID: R. Ci. Inf. e Doc., Ribeirão Preto, v. 1, n. 2, p. 89-102, jul./dez. 2010. 
propostas por Berardi, empenha na produção, na sua atividade, sua competência singular, suas energias comunicativas, inovadoras, criativas, em suma, o melhor de suas capacidades intelectuais.

Por outro lado, este tipo de trabalhador cada vez mais se considera empresário de si mesmo (e acaba sendo, de fato). Essa "introjeção" de formas de comando produz também o duplo efeito de desestruturar e precarizar ainda mais aqueles que são assalariados e fazer com que os autônomos tenham que se ocupar das coberturas e garantias para suas férias, aposentadoria, pensão etc. Do ponto de vista cultural, o trabalhador autônomo é levado a se identificar psicologicamente com a sua função (como os artesãos pré-industriais), porém tendo que arcar com eventuais êxitos ou fracassos, o que acaba tendo um significado não apenas econômico (BERARDI, 2005, p. 51).

\section{Metrópole: lugar da produção biopolítica e da constituição de outros mundos possíveis}

Em seu mais recente trabalho (Commonwealth, 2009) Antonio Negri e Michael Hardt definem o espaço metropolitano, como o lugar da produção biopolítica, espaço da produção do comum, lugar onde as pessoas vivem e trabalham juntas, compartilhando recursos, comunicando, trocando bens e ideias. A metrópole é vista neste caso como o ambiente construído que dá suporte às atividades da multidão, o ambiente social que constitui um repositório de competências, afetos, relações, hábitos, desejos, saberes e circuitos culturais. E o que distingue a metrópole daquela concepção tradicional de cidade é, precisamente, a esfera do comum, que abrange tanto os elementos comuns naturais que constituem o espaço urbano - terra, recursos minerais, água, etc. - quanto os elementos comuns artificiais, que têm a ver com as linguagens, imagens, conhecimentos, afetos, códigos, hábitos e práticas. "Este comum artificial atravessa o território e constitui a metrópole" (op. cit., p. 250).

Para desenvolver esta nova concepção da metrópole, Negri e Hardt fazem uma releitura dos conceitos de biopoder e biopolítica em Foucault, extraindo especificamente deste último um duplo sentido: biopolítica é simultaneamente criação de novas subjetividades (resistência) e força de dessubjetivação. Em outras palavras, a produção biopolítica da riqueza está sendo pensada como acontecimento - o desejo intransigente por liberdade subverte o sistema normativo do poder - e é tanto uma força de ruptura quanto uma força de inovação, que emerge de dentro, que é imanente. 
Esta operação de extrair dos conceitos foucaultianos um outro sentido pode ser aproximada à ideia de devir-menor formulada por Deleuze e Guattari (1997), a criação de linhas de abertura nas proposições teóricas e conceitos de modo a fazer aparecer aquilo que eles têm de mais criativo, de mais instigante e inovador. Neste mesmo sentido de devir-menor, seria útil, para efeitos de nossos propósitos nesta discussão, fazer uma releitura da perspectiva de Milton Santos da metrópole que, de acordo com sua definição, é "o lugar onde é possível viver com sofisticação" (SANTOS ${ }^{4}$ apud SILVA, 2008); um lugar que apresenta um aspecto dinâmico e potente percebido como sofisticação, idéia que não apenas nos convida a pensar a metrópole em um sentido qualitativo e quantitativo, como também afirmativo, isto é, como território de constituição de (outros) mundos possíveis, como meio técnico científico informacional ${ }^{5}$.

Milton Santos (1996) caracteriza o meio natural (também chamado pré-técnico) como aquele da valorização das condições naturais (natureza, cultura, linguagem) que constituem a base material da existência. Segundo o autor, a bem da verdade a técnica sempre existiu, mas os sistemas técnicos não tinham existência autônoma, viviam em simbiose total com a natureza. Só passaram a ter esta autonomia no período da técnica, com a emergência do espaço mecanizado, configurando assim o meio técnico - composto de objetos e artefatos ao mesmo tempo culturais e técnicos, característica que fez com que o espaço fosse cada vez mais constituído de elementos "naturais" e "artificiais". Esses objetos técnicos e "maquínicos" aportaram aos sistemas de produção uma lógica instrumental que acabou colocando em xeque as lógicas naturais, fazendo ganhar força em seu lugar uma lógica instrumental e maquinizada, processo que teve início a partir da segunda guerra mundial e se consolidou nos anos 1970.

Com a emergência da lógica instrumental dos sistemas técnicos, fica evidente que os objetos que compõem este meio tendem a ser principalmente híbridos - ao mesmo tempo técnicos e informacionais. Graças à extrema intencionalidade de sua produção e localização (em rede), os objetos técnicos já surgem como informação (SANTOS, 1996, p. 190). Assim, a ciência, a tecnologia e a informação estão na própria base da produção, da utilização e do funcionamento do espaço vital, constituindo um verdadeiro "tecnocosmo" como diz Milton

\footnotetext{
${ }^{4}$ Entrevista de Milton Santos em 2004, reproduzida em: LEITE, Maria Ângela F. P. (Org.). Encontros: Milton Santos. Rio de Janeiro: Azougue Editorial, 2007.

${ }^{5}$ O meio técnico científico informacional é o que incita, na metrópole contemporânea, um comportamento diferente e "sofisticado", que se traduz em um grau maior e mais avançado de inteligência produtiva: "Aquilo que no mundo atual é feito com maior rentabilidade, com maior produtividade, com maior eficácia, é feito nesse meio" (SANTOS, 1996, p. 91).
} 
Santos, que abarca tanto as grandes cidades e metrópoles quanto o meio rural. Nas suas palavras: "A informação é vetor fundamental do processo social, e os territórios são, desse modo, equipados para facilitar a sua circulação" (ibidem, p. 191).

No meio técnico-científico-informacional que caracteriza a vida e a produção nas metrópoles, as possibilidades de mobilização produtiva do território devem-se mais às condições técnicas e sociais do que propriamente aos recursos naturais ou a uma "vocação" produtiva, e o que possibilita esta transformação é a forma-rede.

\section{A hipótese do território qualificante e a problemática da informação}

A partir das noções de organizações qualificantes e de metrópole como lugar privilegiado da produção biopolítica derivamos a hipótese do território qualificante. Seguindo esta pista, pensamos o território como o lugar onde novas competências são modeladas a partir das ações e das experiências do trabalho cognitivo em rede, competências estas que retornam para o mesmo território na forma de serviços em que a inteligência colaborativa, a criatividade e a inovação são elementos centrais. Com base na ideia de que no capitalismo cognitivo se produz conhecimento por meio de conhecimento e a vida por meio de vida, propomos também que o próprio espaço do território, a partir da atividade e da experiência vivida do trabalho, produz novas qualificações e competências.

Uma outra possível deriva seria articular a problematização feita por Milton Santos a respeito da expansão da dimensão informacional e tecnológica em detrimento da dimensão humana da vida e da produção na globalização com algumas discussões que vêm sendo feitas, no âmbito da ciência da informação, em termos da problemática da própria informação. Tefko Saracevic (1996), por exemplo, constata que os problemas da informação não estão diminuindo mas estão sendo transformados, e que na relação homem-tecnologia, a dimensão tecnológica está em constante expansão e tem se tornado a face mais visível da sociedade da informação. Ao 'linkar' esta problematização aos desafios do trabalho, visto como vetor de impulsão no trabalho autônomo, formulamos algumas perguntas: “A expansão tecnológica resulta em maior eficácia da comunicação e da transmissão e produção de informação?”; “O acesso à tecnologia e aos meios informacionais possibilitam maior liberdade e mobilização produtiva?”; "Qualificam o trabalho e o território onde este trabalho acontece?”. A partir dessas indagações, demos início a um estudo empírico, focalizando o trabalho dos técnicos 
em informática no Rio de Janeiro, que será descrito a seguir.

\section{Os técnicos em informática no Rio de Janeiro}

Uma de nossas premissas iniciais foi a de que o computador é componente fundamental da sociedade da informação e da comunicação, bem como do próprio trabalho no capitalismo cognitivo; os trabalhadores de informática, ou 'infotrabalhadores' como denomina Berardi (2005), em seus diferentes níveis de formação e especialização, são fundamentais para o desenvolvimento do trabalho cognitivo no âmbito das metrópoles. A demanda por esses serviços tem aumentado em virtude da democratização da informática, do barateamento de equipamentos e hardware e da difusão de ambientes operacionais e softwares em sistema de código aberto. Em paralelo à grande difusão da informática nas residências e empresas domésticas, podemos constatar uma grande e constante demanda por serviços de reparos e manutenção (hardware e software). Além disto, é digno de nota o fato de que as redes de prestadores de serviços de informática vão sendo construídas sobretudo a partir de indicações de clientes - o tradicional "boca a boca".

Nosso principal objetivo neste estudo foi, primeiramente, mapear os serviços técnicos e de suporte em informática em relação ao território compreendido pela Região Metropolitana do Rio de Janeiro para em seguida articular às práticas e processos identificados com os conceitos de território qualificante e trabalho cognitivo em rede, no âmbito de uma metrópole como o Rio de Janeiro. Para tanto, distribuímos por e-mail 25 questionários, procurando direciona-los, num primeiro momento, aos técnicos propriamente autônomos, aqueles que não possuem nenhum tipo de vínculo formal de trabalho. Posteriormente, entrevistamos profissionais que trabalham em empresas e também realizam serviços por conta própria para clientes externos, além da jornada regular nas empresas que os contratam. Desses questionários, obtivemos 19 entrevistas, que foram classificadas segundo dois tipos de situação laboral: os que trabalham unicamente como autônomos, alguns com firma estabelecida (6 técnicos); e os que estão formalmente empregados e também exercem atividades por conta própria, 'por fora' do emprego (13 técnicos).

Nos dois grupos entrevistados predominam técnicos do sexo masculino (apenas duas mulheres foram encontradas), jovens (predominância das faixas etárias de 25 a 29 anos e 30 a 35 anos), mais escolarizados no grupo de técnicos contratados por empresas do que os 
profissionais exclusivamente autônomos, entre os quais predomina nível médio (apenas um dos entrevistados possui nível superior). Este último dado, quando cruzado com o tempo de experiência, dá margem a inferir que a menor escolaridade é compensada pelo maior tempo de experiência prática, já que todos os participantes com vínculo empregatício possuem graduação, alguns com especialização, e a maioria iniciou suas atividades profissionais mesmo antes de se formar, sendo contratados como estagiários para adquirir "vivência na empresa".

Por outro lado, um dos autônomos entrevistados declara que há neste meio profissional poucos técnicos com formação especializada e experiência (os que são competentes começam a ser mais requisitados e percebem como mais vantajoso trabalhar por conta própria, apesar dos riscos e a instabilidade inerentes ao fato de terem de construir e administrar suas próprias redes e espaços de atuação), o que parece ser compensado com o atrativo da maior liberdade e flexibilidade para administrar o tempo dedicado ao trabalho aliado à possibilidade de obter rendimentos maiores do que se estivessem trabalhando exclusivamente para uma empresa.

Chamou nossa atenção o fato de os serviços de assistência e manutenção de computadores, softwares e sistemas poderem ser contratados abertamente dentro das empresas onde os técnicos são empregados. Possivelmente, esta maior liberdade para negociar os contratos de serviços 'por fora' no próprio ambiente da empresa esteja relacionada a uma particularidade do próprio meio da informática. Em todo caso, a combinação do modelo do emprego assalariado com o do profissional autônomo parece fazer com que os dois modelos se alimentem reciprocamente, estabelecendo uma relação de mão dupla.

Os técnicos em informática que conjugam os dois modelos de trabalho, ao mesmo tempo em que se qualificam e se aperfeiçoam 'afinando' a percepção do que acontece a sua volta no território, também fazem um deslocamento de perspectiva, no sentido de sair de uma posição de "assujeitamento forçado" (ZARIFIAN, 2003) para uma posição de liberdade, sobretudo na potência do pensamento, da ação, da cooperação dos indivíduos-sujeitos que se constituem como sujeitos justamente nesta relação. Também ajudam a confirmar a conexão entre as novas tecnologias e linguagens, o trabalho em rede, as novas dinâmicas produtivas, e a possibilidade de aprender a partir da instabilidade e das constantes mutações que caracterizam o meio informático, podendo fazer isto coletivamente, nos marcos da cooperação e da comunicação. 


\section{Algumas considerações finais}

Pudemos concluir com nosso estudo que o trabalho dos técnicos em informática é paradigmático de um novo regime do trabalho em que os processos produtivos assumem a forma de um "sistema sociotécnico" caracterizado pelas novas tecnologias da informação e comunicação (MOULIER-BOUTANG, 2007). Essas novas tecnologias impactam tanto os trabalhadores e agentes das dinâmicas produtivas quanto as próprias organizações e empresas localizadas no território desta produção. As organizações que empregam alguns dos profissionais de informática do nosso estudo também são afetadas por esta crescente demanda por digitalização, e neste ambiente, novas demandas, que ultrapassam as fronteiras da atividade fim de cada uma dessas organizações, também emergem. Além disso, o aprendizado do trabalho se dá através da comunicação, o que implica a mobilização de diferentes recursos de linguagem ${ }^{6}$, para aprender a partir da instabilidade e da mudança, para tornar-se ativo diante desta incerteza, no marco da cooperação e da comunicação. Tal ideia está congruente tanto com a nossa hipótese do território qualificante quanto com a definição da cidade biopolítica - um outro nome para a metrópole - defendida por Hardt e Negri:

\footnotetext{
Hoje, finalmente, a cidade biopolítica emerge. Com a passagem à hegemonia da produção biopolítica, o espaço da produção econômica e o espaço da metrópole tendem a se superpor. Não existe mais o muro da fábrica para dividir um espaço do outro, e as "externalidades" não são mais externas ao local da produção que as valoriza. Os trabalhadores produzem através da metrópole, em cada fenda, em cada brecha (2009, p. 251-252).
}

A partir deste primeiro estudo, pretendemos explorar outras formas de trabalho autônomo que se desenvolvem no âmbito da metrópole, e uma possibilidade seria o trabalho dos motoboys. Mas, a hipótese do território qualificante, em conexão com as problemáticas do trabalho e da informação, poderia ser a base para outros estudos e aplicações em contextos mais institucionalizados. O próprio Zarifian se dedica a estudar o trabalho no âmbito de empresas do setor terciário, particularmente o dos trabalhadores de telemarketing. Mas poderíamos também pensar em outros contextos e ambientes de produção e atividade cognitiva, como escolas, universidades, empresas, etc., ou ainda em trabalhos que se realizam em âmbitos mais diretamente ligados aos campos da ciência da informação e da biblioteconomia, como o trabalho dos bibliotecários, por exemplo. Para concluir, deixamos como proposta mais esta questão, que possa talvez nortear futuras conversas e reflexões: em

\footnotetext{
${ }^{6}$ Que seriam, segundo Zarifian (2003), linguagem enunciativa, exploratória, inter-compreensiva, de ação performativa.
}

InCID: R. Ci. Inf. e Doc., Ribeirão Preto, v. 1, n. 2, p. 89-102, jul./dez. 2010. 
que medida a hipótese do território qualificante poderia ser estendida para outros contextos e ambientes?

\section{Referências}

BERARDI, F. A fábrica da infelicidade: trabalho cognitivo e crise da new economy. Rio de Janeiro: DP\&A, 2005. (Coleção Espaços do Desenvolvimento)

CANCLINI, N. G. Consumidores e cidadãos. Rio de Janeiro: Ed. UFRJ, 1995.

CORIAT, B. Pensar pelo avesso: o modelo japonês de trabalho e organização. Rio de Janeiro: Revan: UFRJ, 1994.

DELEUZE, G.; GUATTARI, F. 1730: Devir-intenso, Devir-animal, Devir-imperceptível. In: Mil platôs: capitalismo e esquizofrenia. São Paulo: 34, 1997. v. 4.

GORZ, A. O imaterial: conhecimento, valor e capital. São Paulo: Annablume, 2005. Adeus ao proletariado: para além do socialismo. Rio de Janeiro: Forense Universitária, 1982.

HARDT, M.; NEGRI, A. Commonwealth. Cambridge: Harvard University Press, 2009.

HIRSCHMANN, A. O. Saída, voz e lealdade: respostas para o declínio em empresas, organizações e o estado. São Paulo: Editora Perspectiva, 1973.

LAZZARATO, M. As revoluções do capitalismo. Rio de Janeiro: Civilização Brasileira, 2006. (Coleção A Política no Império)

MARAZZI, C. O lugar das meias. Rio de Janeiro: Civilização Brasileira, 2009. Coleção A Política no Império)

MOULIER-BOUTANG, Y. A bioprodução: o capitalismo cognitivo produz conhecimentos por meio de conhecimento e vida por meio de vida. Revista IHU On-Line, n. 250, 23 abr., p. 513, 2007. Disponível em:

$<$ http://www.ihuonline.unisinos.br/uploads/edicoes/1177359728.74pdf.>.

PIORE, M. J.; SABEL, C. F. The second industrial divide. Nova York: Basic Books, 1984.

RIFKIN, J. O fim dos empregos. São Paulo: Makron Books, 2004.

SANTOS, M. Técnica espaço tempo: globalização e meio técnico-científico informacional. São Paulo: HUCITEC, 1996.

SARACEVIC, T. Ciência da informação: origem, evolução e relações. Perspectivas em Ciência da Informação, Belo Horizonte, v. 1, n. 1, jan./jun., p. 41-62, 1996. 
SILVA, G. O meio técnico-científico informacional e os novos territórios metropolitanos.

Revista Periferia, v. 1, n. 2, 2008.

ZARIFIAN, P. À quoi sert le travail? Paris: La Dispute, 2003.

Organização qualificante e modelos de competência: que razões?: que

aprendizagens? CEDEFOP - Revista Europeia-Formação Profissional, III, n. 5, mai./ago., p. 5-10, 1995. Disponível em:

$<$ http://www.cedefop.europa.eu/etv/Upload/Information_resources/Bookshop/133/5_pt_zarifian.pdf.>

Artigo submetido em 29 out. 2010

Artigo aceito em 29 nov. 2010 